\title{
Russia as a Part of the Global IT Market: is There a Chance for a Breakthrough?
}

\author{
Alexander Demidenko*, Alexander Demidenko, and Igor Demidenko \\ Bryansk State Technical University, 241035 Bryansk, Russia
}

\begin{abstract}
The global information technology market is growing every year. Russia has great resource potential and a developed material and technical base to become one of the leaders in this area. Now Russia occupies a very modest place in the global IT industry. The situation is gradually changing. The Russian digital industry is growing much faster than the economy as a whole. However, in order to catch up with the leading countries, the IT sector must develop even faster. In recent years, the state has begun to play a decisive role in the economy therefore, the state has been tasked with bringing the Russian digital economy into the ranks of world leaders. This requires significant transformations and changes in the state model for creating a digital economy.
\end{abstract}

\section{Introduction}

Today the world is on the verge of a new technological revolution, which again change our world beyond recognition. This time with the help of information technologies. Already, in the ranking of the most valuable companies in the world in terms of total market capitalization, 6 out of 10 companies are fully or significantly associated with information technologies. The COVID-19 pandemic has shown that humanity, in principle, is no longer able to function normally without the use of information technology in one form or another.

The digital economy is growing at a staggering pace due to its ability to collect, use and analyze huge amounts of digital data in any format and from any area of our society. In 1992, IP-based global Internet traffic was roughly 100 gigabytes per day, and in 2017 it was 45,000 gigabytes per second. According to experts, the volume of global traffic by 2022 will grow more than 3 times to 150,700 gigabytes per second. Such a large-scale growth will be ensured by the expansion of the geography of users and the beginning of the widespread introduction of IoT and artificial intelligence technologies [1].

The share of the digital economy in the GDP of the most developed countries continues to grow steadily. According to the McKinsey consulting agency ("Digital Russia" research), in 2016, the size of the digital economy in the US reached $10.9 \%$ of GDP or $\$ 2$ trillion, China - 10\% of GDP or \$ 1.2 trillion, the European Union - $8 \%$ of GDP or \$ 1.3 trillion [2]. Industries directly related to the ubiquity of high-speed Internet are experiencing rapid growth. A striking confirmation is the dynamics of the growth of e-commerce in recent years.

\footnotetext{
* Corresponding author: aa.demidenko@yandex.ru
} 
If in 2014 it was estimated at $\$ 1.3$ trillion, then in 2020 it is already at $\$ 4.1$ trillion (Fig. 1). The Internet of Things (IoT) market is also developing dynamically. In 2018, its volume was $\$ 212$ billion. This market is projected to grow at $25 \%$ per year and will reach $\$ 1.3$ trillion by 2026 . The artificial intelligence market in 2017 was estimated at about $\$ 13.4$ billion, and by 2022 the total volume of the AI technologies market will increase to $\$ 52.5$ billion [3]. And these are the most popular technologies that we hear about every day. The overall contribution of IT technologies to the future of the world economy does not lend itself to any calculation at all. It's just invaluable.

An indicator that today IT technologies are the locomotive of the world economy is the annual increase in their share in world GDP by almost $18 \%$, and in developed countries by $7 \%$. According to forecasts by The Boston Consulting Group, the volume of the digital economy by 2035 could reach 16 trillion.

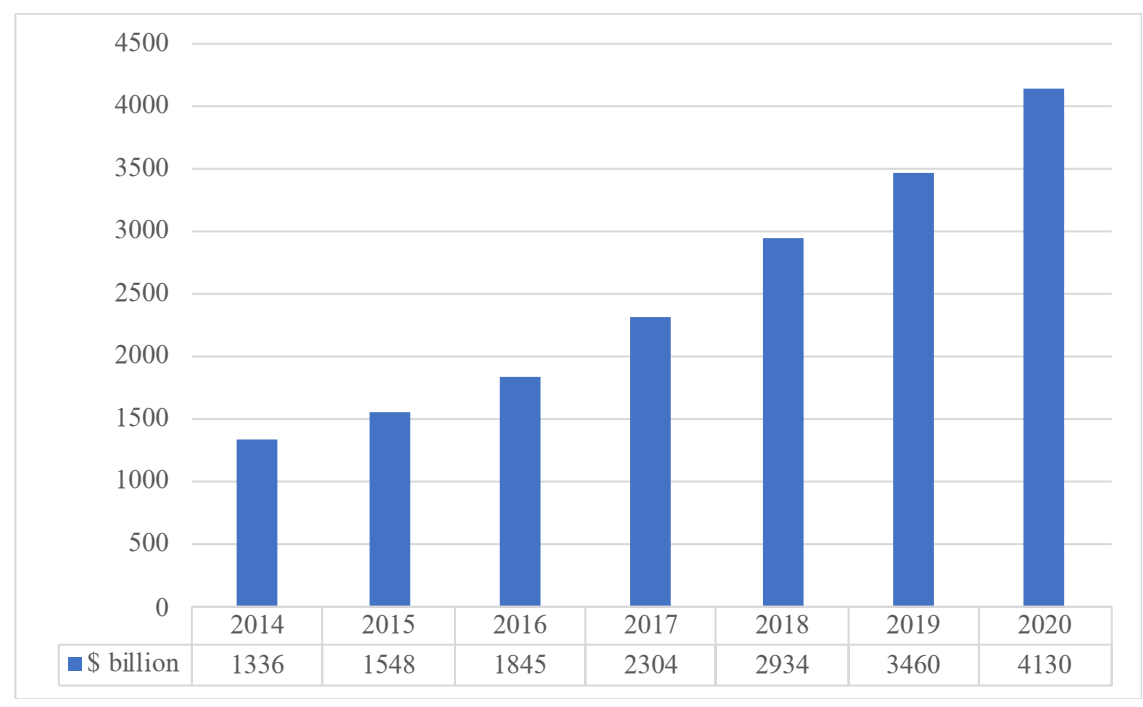

Fig. 1. Growth in the volume of e-commerce in the world.

Therefore, today the prospects for digitalization of the world economy have not yet been exhausted, the market is open for new projects. And any country has a chance to become a leader in this area in the near future.

But what place does Russia occupy in the global market of IT technologies today, and does it have a chance, if not to lead, then at least take a worthy place among the most technologically advanced countries?

\section{Russia's Place in the Global IT Market}

In Russia, at the official level, the share of the information industry in GDP is not published, but is maintained by the Russian Association for Electronic Communications (RAEC). According to their calculations, in 2017, the total contribution of the digital economy to Russia's GDP was 3.9\%, in $2018-5.1 \%$, in $2019-5.8 \%$. Positive dynamics is visible to the naked eye, but Russia still remains in this indicator 1.5-2 times from the USA, China and the EU countries [5].

Today the IT sector is the locomotive of the Russian economy. According to the HSE, for the period from 2010 to 2019 , the gross value added of the Russian IT industry more than doubled, to 945 billion rubles (Fig. 2). Annually, the aggregate value added of the Russian 
IT sector's products grew by an average of $10 \%$, while the analogous indicator for the GDP as a whole was only $1.9 \%$ [6].

Russian producer of IT services have significantly strengthened their positions not only in the domestic but also in the foreign market: thus, the export of IT services has tripled over the period under review. In recent years, a trend has emerged for an excess of exports over imports: in 2017 by $1 \%$, in $2018-15 \%$, in $2019-25 \%$. Oddly enough, the United States is the main consumer of Russian IT products. In 2018, \$ 1,310 million, or almost a third of all Russian exports of IT products, fell to the United States, which suggests that Russian software is absolutely competitive in the global market [7].



Fig. 2. Volume indices of gross value added ( $\%$ of the previous year; constant prices).

Despite the significant growth rates of the IT sector, the export of Russian IT services in dollar terms remains very modest. According to information for 2018, it amounted to only $\$$ 4.1 billion. Russia's neighbors in this list are Italy ( $\$ 4.3$ billion) and Romania ( $\$ 3.9$ billion). By comparison, the United States exported \$ 24 billion worth of computer services, and Ireland $\$ 78$ billion! If we assume that the Russian IT sector will continue to grow by an average of $10 \%$ per year, then Russia will never be able to catch up with the United States. This fact is confirmed by the number of new IT companies. According to a research by the Boston Consulting Group, Russia accounted for 3\% of the total number of IT companies founded in developing countries since 2014 [8].

There are also problems in the domestic market. In Russia, the volume of investments of private companies in digitalization is only $2.2 \%$ of GDP, while in the USA it reaches $5 \%$, in Western Europe $-3.9 \%$. In addition, if we consider the costs of digitalization in more detail, it turns out that approximately $85 \%$ of all IT costs are generated by the largest Russian companies. That is, small and medium-sized businesses are practically not involved in digitalization processes. Although such statistics clearly reflect the insignificant contribution that SMEs make to the Russian economy (2017 - 22\% of GDP, $2018-20.2 \%$ of GDP).

Russia lags behind the leading countries in terms of the number of IT-personnel. According to data for 2019, the share of IT specialists in the total economically active population is $2.4 \%$, or only 1.8 million people. For comparison, in the UK it is $5 \%$, in Finland - 7\%, and in the Czech Republic - 4\%. Annually, there are statements about a catastrophic shortage of qualified IT specialists, but the situation has not changed significantly [9]. 
However, Russia has the potential for explosive growth of the IT industry, and such companies as Yandex, Mail.ru Group, 1C clearly confirm this. But what is stopping our companies?

\section{What prevents Russian companies from becoming leaders?}

The main reasons for Russia's lag behind the leading countries in the development of the digital economy are:

1) an unfavorable environment for doing business (especially for small companies with limited resources),

2) the slow process of introducing innovations in the economy,

3) outdated legislation that often hinders progress,

4) imbalance in the development of regions. Most of the revenue of Russian IT companies operating in the domestic market. are generated by Moscow and St. Petersburg. The rest of the regions are much less involved in the processes of active digitalization [10].

The government is aware of the current situation and several government programs have been developed and are actively being implemented to reduce Russia's lag in the field of information technologies.

Firstly, this is the national program "Digital Economy of the Russian Federation". The most significant tasks that this program is aimed at, the following can be distinguished: an increase in internal costs for the development of the digital economy by at least three times compared to 2017, creation of a stable and secure information and telecommunications infrastructure, using of predominantly Russian software by government agencies, local governments and organizations. More than 1.6 trillion rubles have been allocated for the program. The program implements until the end of 2024.

Secondly, this is the Strategy for the Development of the Information Society in the Russian Federation for 2017-2030. This is a document that defines the general directions and principles for the development of the digital economy and information society in the Russian Federation.

Third, these are programs for financing promising projects from the Fund for Assistance to Innovation, Agency for strategic initiatives (ASI), Russian Venture Company (RVC), Skolkovo Foundation, Internet Initiatives Development Fund (IIDF), VEB-Ventures, JSC RUSNANO, Russian Direct Investment Fund (RDIF), Russian Export Center (REC).

However, all these measures are unlikely to help significantly change the situation. Skolkovo, which was originally conceived as Russian alternative to Silicon Valley, for 10 years has not been able to even remotely approach the original. And all because Russian Government is trying to artificially stimulate the IT industry without creating a favorable business climate [11].

A "favorable business climate" is understood as the absence of significant geopolitical risks that could dramatically worsen the economic situation in the country, stability and adequacy of legislation, freedom of doing business, as well as the independence of the judiciary and low levels of corruption. Russia does not have these things at the moment. Political adventures can at one moment bring down the exchange rate of ruble and close access to international markets for Russian IT companies. Extremely changeable legislation does not give confidence that the "rules of the game" will not change dramatically, and absolutely unexpectedly. In addition, the repressive nature and ill-conceivedness of modern legislation.

At the moment, non-state Russian IT industry is developing in spite of everything, and despite the huge potential, it is not possible to realize it in the current conditions. This requires significant reforms. 


\section{Areas of Support for the Russian IT Industry}

Russia is an integral part of the world community and all socio-economic processes taking place in it. The Russian economy is very multifaceted and the information technology area is one of its many branches. Therefore, it is impossible to create a powerful and competitive IT industry in a vacuum. This requires both targeted support measures and stable growth of the country's GDP as a whole. However, now we focus on those areas of support for the Russian IT industry, which can bring tangible results in the near future.

Firstly, one of the main features of the Russian IT market is that it is poorly capitalized. Several hundred large and medium-sized companies are represented there, of which a little more than 20 have annual revenues above 6 billion rubles. This results in insufficient investment in its own development and development of new technologies, lack of own funds for project investment, as well as lack of opportunities for rapid growth through mergers and acquisitions of other companies. It follows from this that at the current stage, the IT sector, like no one else, needs government assistance. However, now in Russia, in fact, there is no comprehensive program for supporting the digital industry. The Digital Economy program has practically no tasks and indicators related to the development of the digital economy as a whole (for example, the share of high-tech jobs in the employment structure). There are also no goals to bring Russian technologies to global markets. The program is largely focused on digitalizing basic government services and creating an independent information infrastructure. Therefore, now Russia really needs a full-fledged state program for the development of the digital economy and high-tech exports [12].

Secondly, it is necessary to reduce the tax burden for IT companies. The law that cuts taxes for Russian IT companies, signed this summer, caused a very mixed reaction. Along with a decrease in social insurance contributions from 14 to $7 \%$ and a decrease in income tax from 20 to $3 \%$, VAT exemptions were also canceled. There is almost no VAT in the structure of expenses of IT companies, therefore they cannot claim a deduction.

Thirdly, it is necessary to reform the judicial system. The current judicial system does not adequately protect private property and does not help protect entrepreneurs from illegal prosecution.

Fourthly, the state needs to become more open and flexible and listen much more to the opinion of business and the expert community. A good example is the problems with the allocation of frequencies for the deployment of $5 \mathrm{G}$ networks. The Ministry of Defense of the Russian Federation refused to allocate the $4-3.8 \mathrm{GHz}$ frequency range to cellular operators, which is used to deploy fifth-generation networks around the world. This will lead to a manifold increase in the cost of deploying networks. $5 \mathrm{G}$ networks built on the frequencies allocated by the military will not pay off until at least 2040 and will significantly slow down the modernization of the economy.

\section{Conclusions}

Widespread digitalization is a real chance for the Russian economy to finally get off the oil needle, and this goal justifies any means.

The digital economy in Russia today is at a stage of rapid development. How fast the IT sector is growing in relation to GDP confirms this. The world is on the verge of a digital revolution and every day it demands more and more new ideas, non-standard solutions and innovative products. Russia has all the capabilities to meet this demand.

However, today the digital economy in Russia occupies an insignificant share in the country's GDP and an even smaller share on a global scale, so the IT sector must grow not just quickly, but very quickly. This is the only way to overcome the emerging technological lag in Russia. 
Now the role of the state in the life of the country is very significant and therefore Russian Government must solve this problem. For this it is necessary in practice to change the attitude of the state towards information technologies. Now IT is viewed mostly as an infrastructure to support the work of the state apparatus, and not at all as a locomotive of the economy, the basis of the country's future welfare and one of the elements of geopolitical influence. The state should meet not only IT companies, but the entire business: to become more open and liberal, and most importantly, think and work for the future, sometimes sacrificing something today to get much more tomorrow.

\section{References}

1. Report «Digital Economy: Global Trends and Practice of Russian Business», HSE (2017)

2. Digital Russia: a new reality, McKinsey (2017)

3. R. Kapeliushnikov, Russian Journal of Economics, 5 (2019)

4. Russia Online: Four Priorities for a Breakthrough in the Digital Economy, BCG (2017)

5. Economy of Runet, Digital economy of Russia 2019, RAEC (2020)

6. M. Dabrowski, Russian Journal of Economics, 5 (2019)

7. The digital potential of the EDB member countries, Integration research center (2019)

8. V. I. Golovchenko, The regional aspect of solving the problems of the digital economy in modern Russia, Basis (2019)

9. G.I. Abdrakhmanova, K. O. Vishnevsky, L. M. Gokhberg, Digital economy 2020: a short statistical digest, HSE (2020)

10. Lending to Russian Small Businesses: From a Traditional to a Partnership-based Banking Model, 24(2) (2020)

11. V.A. Tsvetkov, N.S. Ziyadullaev, K.Kh. Zoidov, K.S. Yankauskas, Problems and prospects for the development of the digital economy in Russia. Strategic trends in the transformation of socio-economic systems within the digital economy, MEI RAS (2018)

12. A. Balaev, Russian Journal of Economics (2019) 